\title{
Characterization of 3,4-Methylenedioxymethamphetamine (MDMA) Enantiomers In Vitro and in the MPTP-Lesioned Primate: $R$-MDMA Reduces Severity of Dyskinesia, Whereas $S$-MDMA Extends Duration of ON-Time
}

\author{
Philippe Huot, ${ }^{1,2}$ Tom H. Johnston, ${ }^{1}$ Katie D. Lewis, ${ }^{3}$ James B. Koprich, ${ }^{1}$ M. Gabriela Reyes, ${ }^{1}$ Susan H. Fox,,${ }^{1,2}$ \\ Matthew J. Piggott, ${ }^{3}$ and Jonathan M. Brotchie ${ }^{1}$ \\ ${ }^{1}$ Toronto Western Research Institute and ${ }^{2}$ Division of Neurology, Movement Disorder Clinic, Toronto Western Hospital, University Health Network, \\ Toronto, Ontario M5T 2S8, Canada, and ${ }^{3}$ School of Biomedical, Biomolecular and Chemical Sciences, The University of Western Australia, Perth \\ 6009 , Australia
}

L-3,4-Dihydroxyphenylalanine (L-DOPA) is the most effective treatment for Parkinson's disease, but long-term L-DOPA administration is marred by the emergence of motor complications, namely, dyskinesia and a shortening of antiparkinsonian benefit (wearing-OFF). 3,4-Methylenedioxymethamphetamine (MDMA) is unique in that it exerts antidyskinetic effects and may enhance antiparkinsonian actions of L-DOPA. MDMA is composed of two enantiomers with different pharmacological profiles; here, we describe a novel enantiospecific synthesis of the two enantiomers and expand on the previous characterization of their pharmacology. R-MDMA (rectus-MDMA) is relatively selective for $5-\mathrm{HT}_{2 \mathrm{~A}}$ receptors, whereas $S$-MDMA (sinister-MDMA) inhibits both serotonin (SERT) and dopamine transporters (DAT; SERT/DAT ratio of 10 to 1$)$. $R$ - or $S$-MDMA (1, 3, and $10 \mathrm{mg} / \mathrm{kg}$, s.c.) was administered in combination with L-DOPA (15 mg/kg, s.c.) to six female common marmosets (Callithrix jacchus) rendered parkinsonian by MPTP (1-methyl-4-phenyl-1,2,3,6tetrahydropyridine) administration. Motor disability, including parkinsonism and dyskinesia, and duration of antiparkinsonian benefit (ON-time) were evaluated. After the administration of $R$-MDMA ( 3 and $10 \mathrm{mg} / \mathrm{kg}$ ), the severity of peak-dose dyskinesia was decreased (by 33 and 46\%, respectively; $p<0.05$ ); although total ON-time was unchanged ( 220 min), the duration of ON-time with disabling dyskinesia was decreased by $90 \mathrm{~min}$ when compared to L-DOPA alone (69\% reduction; $p<0.05) . S$-MDMA ( $1 \mathrm{mg} / \mathrm{kg}) \mathrm{increased} \mathrm{the} \mathrm{total}$ ON-time by 88 min compared to L-DOPA alone ( $34 \%$ increase; $p<0.05$ ), though dyskinesia were exacerbated. These data suggest that racemic MDMA exerts simultaneous effects, reducing dyskinesia and extending ON-time, by 5-HT $2 \mathrm{~A}$ antagonism and SERT-selective mixed monoamine uptake inhibition, which arise from its $R$ and $S$ enantiomers, respectively.

\section{Introduction}

The motor manifestations of Parkinson's disease (PD) are caused by striatal dopamine depletion (Hornykiewicz and Kish, 1987). Dopamine replacement therapy with L-3,4-dihydroxyphenylalanine (LDOPA) is the most effective treatment against the motor symptoms of PD. However, with increased duration of therapy, motor compli-

Received March 7, 2011; revised March 22, 2011; accepted March 26, 2011.

Author contributions: T.H.J., S.H.F., M.J.P., P.H., and J.M.B. designed research; P.H., T.H.J., K.D.L., M.G.R., and J.B.K. performed research; P.H., K.D.L., M.J.P., and J.M.B. analyzed data; P.H., M.J.P., and J.M.B. wrote the paper.

This work was supported by the Cure Parkinson Trust and the Krembil Neuroscience Fund. P.H. was supported by fellowships from the Edmond J. Safra Philanthropic Foundation and the Parkinson Society Canada. K.D.L. was the recipient of an Australian Postgraduate Award.

The authors declare no competing financial interests. S.H.F. has received consultancy and speaker fees from Acadia, Asubio, Merz, Novartis, Teva, and Biovail. T.H.J. and J.B.K. have received consultancy fees from Atuka Ltd. J.M.B. has received consultancy fees from and holds an equity position in Atuka Ltd. All other authors have no financial disclosures.

Correspondence should be addressed to Jonathan M. Brotchie, Toronto Western Research Institute, McLaughlin 11-419, Toronto Western Hospital, 399 Bathurst Street, Toronto, ON M5T 2S8, Canada. E-mail: brotchie@uhnres.utoronto.ca.

DOI:10.1523/JNEUROSCI.1171-11.2011

Copyright $\odot 2011$ the authors $\quad 0270-6474 / 11 / 317190-09 \$ 15.00 / 0$ cations develop and afflict 95\% of patients after 15 years (Hely et al., 2005).

In an anecdotal report (BBC, 2001), 3,4-methylenedioxymethamphetamine (MDMA; “ecstasy"), a widely used drug of abuse, reduced severity of L-DOPA-induced dyskinesia and increased duration of antiparkinsonian benefits (ON-time) in a patient with early-onset PD. Of these two actions, the antidyskinetic activities of MDMA were confirmed in subsequent animal studies. Thus, when added to L-DOPA therapy, MDMA reduced dyskinesia-like behaviors in 6-hydroxydopamine (6-OHDA)-lesioned rats (Bishop et al., 2006) and dyskinesia in the 1-methyl-4-phenyl-1,2,3,6-tetrahydropyridine (MPTP)-lesioned marmoset (Iravani et al., 2003).

The precise mechanism by which MDMA alleviates dyskinesia is unknown. MDMA is composed of two enantiomers with distinct pharmacological profiles. $R$-MDMA (rectus-MDMA) has affinity for the serotonergic type $2 \mathrm{~A}\left(5-\mathrm{HT}_{2 \mathrm{~A}}\right)$ receptors (Lyon et al., 1986), at which it acts as a low efficacy partial agonist (Nash et al., 1994). $S$-MDMA (sinister-MDMA) binds to the serotonin (5-HT; SERT), dopamine (DAT), and noradrenaline transporters (NET), inhibits monoamine reuptake, and reverses the action of the transporters 


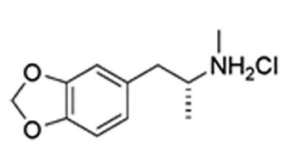

R-MDMA.HCl
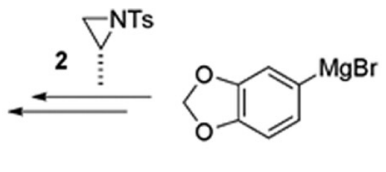

1
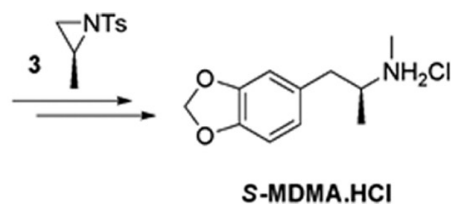

natant was removed and the pellet resuspended in ice-cold Tris buffer, $\mathrm{pH}$ 7.4. Protein concentration was determined by the Lowry variant of the Folin's phenol reagent method (Lowry et al., 1951).

Radioligands and drugs. $\left[{ }^{3} \mathrm{H}\right]-\mathrm{WAY}-100,635$ (specific activity, $74 \mathrm{Ci} / \mathrm{mm}$ ) was purchased from American Radiolabeled Chemicals. $\left[{ }^{3} \mathrm{H}\right]-$ Ketanserin (specific activity, $67 \mathrm{Ci} / \mathrm{mm}$ ), $\left[{ }^{3} \mathrm{H}\right] 1$-[2-(diphenylmethoxy)ethyl]-4-(3-phe-

(Verrico et al., 2007). Previous pharmacological studies have suggested that $5-\mathrm{HT}_{2 \mathrm{~A}}$ receptors might be involved in the genesis of dyskinesia and thus might support the involvement of $R$-MDMA in antidyskinetic actions. For example, the nonselective $5-\mathrm{HT}_{2 \mathrm{~A}}$ antagonists clozapine and quetiapine reduced dyskinesia-associated behaviors in the 6-OHDA-lesioned rodent and dyskinesia in the MPTP-lesioned primate (Oh et al., 2002; Visanji et al., 2006). In human studies, low-dose clozapine alleviated dyskinesia (Durif et al., 2004). The $5-\mathrm{HT}_{2 \mathrm{~A}}$ receptor inverse agonist pimavanserin (ACP103) also reduced dyskinesia in MPTP-lesioned macaques (Vanover et al., 2008) and human PD subjects (Roberts, 2006). On the other hand, an indirect action on 5- $\mathrm{HT}_{1 \mathrm{~A}}$ (serotonergic type $1 \mathrm{~A}$ ) receptors, mediated by MDMA-induced 5-HT release, was suggested to play a role in MDMA antidyskinetic actions (Bishop et al., 2006); such a mechanism could be mediated by $S$-MDMA.

This study was undertaken to determine which, if either, of the two enantiomers of MDMA was responsible for the antidyskinetic properties of the compound. We hypothesized that the antidyskinetic action of racemic MDMA was primarily mediated by its $R$ enantiomer. In the current study, we executed a novel enantiospecific synthesis of $R$ - and $S$-MDMA; established their pharmacological profile in vitro at $5-\mathrm{HT}_{2 \mathrm{~A}}$ receptors and monoamine transporters using selective, well-characterized ligands; and administered them, in combination with L-DOPA, to MPTPlesioned common marmosets.

\section{Materials and Methods}

\section{$\mathrm{R}-$ and S-MDMA synthesis}

Methodology developed by Nenajdenko et al. (2001) was adapted to the synthesis of $R$ - and $S$-MDMA. The key step involved the enantiospecific and high-yielding ring opening of the enantiopure aziridines $\mathbf{2}$ and $\mathbf{3}$, conveniently derived from $\mathrm{L}$ - and D-alanine, respectively, by the Grignard reagent 1 (Fig. 1). Subsequent methylation and detosylation provided $R$ and S-MDMA, which were converted to their hydrochlorides for pharmacological characterization.

\section{In vitro pharmacology}

Tissue preparation. Female Sprague Dawley rats (250-275 g, Charles River) were housed, with access to food and water ad libitum, in a temperature- $\left(19-21^{\circ} \mathrm{C}\right)$, humidity- $(55 \%)$, and light-controlled $(12 \mathrm{~h}$ light/dark cycle; lights on 7:00 A.M.) environment. All procedures were performed in accordance with an Institutional Animal Care and Use Committee (IACUC) approved by University Health Network Animal Care Committee and in accordance with the regulations defined by the Canadian Council on Animal Care. All reasonable efforts were made to reduce animal numbers used and minimize their suffering.

Rats were killed by decapitation after $\mathrm{CO}_{2}$ narcosis. Brains were immediately removed and placed into ice-cold Krebs' buffer containing the following (in mM): $134 \mathrm{NaCl}, 5 \mathrm{KCl}, 1.3 \mathrm{CaCl}_{2}, 1 \mathrm{MgSO}_{4}, 25 \mathrm{NaHCO}_{3}$, $1.25 \mathrm{KH}_{2} \mathrm{PO}_{4}$, and 10 glucose. Various brain regions (cerebral cortex, striatum, cerebellum, and remaining brain) were dissected on ice and placed separately into ice-cold Tris buffer, $\mathrm{pH} 7.4$, before probe sonication on ice. Brain homogenates were then centrifuged $\left(20,000 \times g_{\max }\right)$ for $20 \mathrm{~min}$ at $4^{\circ} \mathrm{C}$, resuspended into ice-cold Tris buffer, $\mathrm{pH} 7.4$, and recentrifuged for $20 \mathrm{~min}$ at $4^{\circ} \mathrm{C}\left(20,000 \times g_{\text {max }}\right)$. After centrifugation, supernatant was removed, and the pellet was resuspended in ice-cold Tris buffer, $\mathrm{pH} 7.4$, vortexed, and placed in a $37^{\circ} \mathrm{C}$ water bath for $20 \mathrm{~min}$. After a final centrifugation step $\left(20 \mathrm{~min}\right.$ at $\left.4^{\circ} \mathrm{C} ; 20,000 \times g_{\max }\right)$, super- nylpropyl)piperazine ([ $\left.{ }^{3} \mathrm{H}\right]-$ GBR 12935$)$ (specific activity, $\left.43 \mathrm{Ci} / \mathrm{mM}\right)$, $\left[{ }^{3} \mathrm{H}\right]$-nisoxetine (specific activity, $85 \mathrm{Ci} / \mathrm{mm}$ ), and $\left[{ }^{3} \mathrm{H}\right]$-citalopram (specific activity, $84 \mathrm{Ci} / \mathrm{mm}$ ) were purchased from PerkinElmer. 8-Hydroxy-2(dipropylamino)tetralin (8-OHDPAT), 1-(2-(bis(4-fluorophenyl)methoxy) ethyl)-4-(3-phenylpropyl)piperazine (GBR 12909), 3-((4-(4-chlorophenyl)-1-(piperazinyl)methyl)-1 $H$-pyrrolo[2,3-b] pyridine (L-745,870), maprotiline, paroxetine, and spiperone were purchased from Tocris Bioscience.

Receptor and transporter binding assays. The receptor and transporter binding assays performed in the current study targeted only the receptor/ transporters to which racemic MDMA was shown to display affinity in a previous experiment performed by our group (Gandy et al., 2010). Even though MDMA did not display high affinity at $5-\mathrm{HT}_{1 \mathrm{~A}}$ receptors in that experiment, we have nevertheless performed $5-\mathrm{HT}_{1 \mathrm{~A}}$ receptor binding for both enantiomers, as it has been suggested that MDMA's antidyskinetic effect involved a $5-\mathrm{HT}_{1 \mathrm{~A}}$-mediated mechanism (Bishop et al., 2006). Binding parameters relating to brain region used, ligand and ion concentration, as well as incubation conditions employed for each of the assays are summarized in Table 1. Incubations were conducted in $380 \mu \mathrm{l}$ 96-well plates. Brain membranes were incubated with $R$ - and $S$-MDMA ( $1 \mathrm{nM}$ to $1 \mu \mathrm{M}$ ) in the presence of the radioligand.

After incubation, the membranes were rapidly washed in $50 \mathrm{~mm}$ Tris buffer, pH 7.4 (20 s wash at $10 \mathrm{ml} / \mathrm{s}$ ) and filtered under vacuum through Whatman glass fiber (G/F) filters (GE Healthcare Canada) presoaked in $50 \mathrm{~mm}$ Tris buffer, pH 7.4, using a cell harvester (Brandel). For NET and DAT assays, G/F filters were presoaked in a $50 \mathrm{~mm}$ Tris, $\mathrm{pH}$ 7.4, solution containing $0.1 \%$ polyethyleneimine (Sigma-Aldrich) and were washed with a $50 \mathrm{~mm}$ Tris solution containing $0.1 \%$ bovine serum albumin (Sigma-Aldrich). Filters were then immersed in scintillation fluid (Ecoscint), and radioactivity was determined with a scintillation counter (Beckman Coulter) as counts per minute.

Determination of R- and S-MDMA affinity at selected receptor/transporters. Values of displacement by $R$ - and $S$-MDMA were determined in three independent experiments, each in triplicate, and displacement was expressed as a percentage of specific binding. Dose-response curves were constructed and the half-maximal inhibitory concentration $\left(\mathrm{IC}_{50}\right)$ was determined via nonlinear regression analysis using the software GraphPad Prism 5.03. The inhibition constant $\left(K_{\mathrm{i}}\right)$ was calculated using the Cheng and Prusoff (1973) equation.

\section{Behavioral assessment of $\mathrm{R}$ - and S-MDMA in the MPTP-lesioned nonhuman primate}

Induction of parkinsonism and dyskinesia in the common marmoset. Six female common marmosets (Callithrix jacchus; Harlan) weighing 350$500 \mathrm{~g}$ were housed in groups of two or three under conditions of controlled temperature $\left(25 \pm 2^{\circ} \mathrm{C}\right)$ and a $12 \mathrm{~h}$ light/dark cycle (lights on at 8:00 A.M.). Animals were cared for in accordance with an IACUC approved by University Health Network Animal Care Committee protocol and with the regulations defined by the Canadian Council on Animal Care. Animals had unlimited access to food, fresh fruit supplements, and water, and their home cage was enriched with primate toys, perches, and auditory stimuli. Before the start of studies, animals were acclimatized to handling, administration of subcutaneous treatments, as well as transfer to observation cages for assessment of behavior.

Animals were rendered parkinsonian by administration of MPTP hydrochloride (Sigma-Aldrich) according to a standard protocol (Silverdale et al., 2005) (2 mg/kg, s.c., daily, for 5 consecutive days). After MPTP treatment, marmosets entered a 12 week recovery period to allow parkinsonian symptoms to develop and stabilize. The animals included in the study exhibited a severe and homogeneous degree of parkinsonism 
Table 1. Experimental parameters for receptor/ transporters binding assays

\begin{tabular}{|c|c|c|c|c|c|}
\hline Receptor/transporter & Brain tissue & Radioligand (concentration) & Nonspecific displacer & Ionic conditions & Incubation parameters \\
\hline $5-\mathrm{HT}_{1 \mathrm{~A}}$ & cerebral cortex & {$\left[{ }^{3} \mathrm{H}\right]-W A Y-100,635$ (3.0 nм) } & 8-OHDPAT & & $60 \mathrm{~min}$, ambient $\mathrm{T}^{\circ}$, in the presence of $10 \mathrm{~nm} \mathrm{~L}-745,870$ \\
\hline $5-\mathrm{HT}_{2 \mathrm{~A}}$ & cerebral cortex & {$\left[{ }^{3} \mathrm{H}\right]$-ketanserin $(2.5 \mathrm{~nm})$} & spiperone & & $45 \mathrm{~min}, 4^{\circ} \mathrm{C}$ \\
\hline NET & cerebellum & {$\left[{ }^{3} \mathrm{H}\right]$-nisoxetine (2.0 nм) } & maprotiline & $300 \mathrm{mmNaCl}, 5 \mathrm{mmKCl}$ & $60 \min , 4^{\circ} \mathrm{C}$ \\
\hline DAT & striatum & [ $\left.{ }^{3} \mathrm{H}\right]-$ GBR 12935 (5.6 nм) & GBR 12909 & $125 \mathrm{~mm} \mathrm{NaCl}$ & $45 \mathrm{~min}$, ambient $\mathrm{T}^{\circ}$ \\
\hline
\end{tabular}

Brain tissue concentration remained fixed for all of the experiments ( $2 \mathrm{mg} / \mathrm{ml}$ of protein). The nonspecific displacer concentration remained fixed for all of the experiments ( $10 \mu \mathrm{M})$. For 5 - $\mathrm{HT} \mathrm{IA}_{\mathrm{A}}$ receptor binding, $10 \mathrm{~nm} \mathrm{~L}-745,870 \mathrm{was}$ added to each well to prevent [ $\left.{ }^{3} \mathrm{H}\right]-W A Y-100,635$ from interacting with dopaminergic $\mathrm{D}_{4}$ receptors (Chemel et al., 2006). Such a concentration of L-745, 870 was chosen because it is $>20$-fold over the $K_{\mathrm{i}}$ for $\mathrm{D}_{4}$ receptors $(0.43 \mathrm{~nm}$ ), while being $>10$ times under the $K_{\mathrm{i}}$ of L-745,870's next target (sigma receptors, $130 \mathrm{~nm}$ ) (Patel et al., 1997). The remainder of brain (ROB) corresponds to the brain areas remaining following dissection of the cortex, striatum, and cerebellum. This encompasses the raphe nuclei, substantia nigra, diencephalon, globus pallidus, hippocampus, and subcortical white matter. Ambient $\mathrm{T}^{\circ}, 20-22^{\circ} \mathrm{C}$.

[median score of $90 \pm 1.5$ (interquartile interval) when assessed in the OFF state for a 30 min period, during which the maximal possible parkinsonian score was 108].

Treatment-related complications including dyskinesia and psychosislike behaviors were induced by twice-daily treatment with oral Prolopa (L-DOPA/benserazide, 15/3.75 mg/kg; Hoffmann-La Roche) for a minimum of $30 \mathrm{~d}$. This treatment regimen has been demonstrated previously to produce a stable model of L-DOPA-induced complications (GomezRamirez et al., 2006). The animals used in the current study were not drug naive and had been used in previous studies assessing the antidyskinetic potential of adjunct therapies. However, there were several weeks of washout between the end of the previous study and the start of the current one. In addition, before beginning the current study, a baseline parkinsonian score and response to L-DOPA were obtained; this baseline parkinsonian score and response to L-DOPA were reassessed at the completion of the study and had remained constant between the start and the end of the study (data not shown).

Administration of $\mathrm{R}$ - and $\mathrm{S}-M D M A$, in combination with $L-D O P A$, to parkinsonian marmosets. On days of behavioral assessment, at 9:00 A.M., marmosets were administered L-DOPA/benserazide (15/3.75 mg/kg, s.c.; Sigma-Aldrich) in combination with either vehicle $(\mathrm{NaCl}, 0.9 \%)$ or $R$ - or $S$-MDMA hydrochloride (equivalent to 1,3 , and $10 \mathrm{mg} / \mathrm{kg}$ free base, s.c.). The drug administration schedule was randomized according to a Latinsquare design, in which all animals were administered all treatments on different days. Immediately after administration of treatment, marmosets were placed individually into observation cages $(0.8 \times 0.8 \times 0.7 \mathrm{~m})$ containing food, water, and a wooden perch, and left undisturbed for the duration of the experiment. Behavior was recorded on DVD for $6 \mathrm{~h}$ and analyzed post hoc by a movement disorders neurologist blinded to the treatment given. A minimum of $48 \mathrm{~h}$ was left between each treatment in any animal.

Behavioral analysis. Methods for assessment of behavior were described previously in detail (Fox et al., 2006; Gomez-Ramirez et al., 2006; Visanji et al., 2006; Fox et al., 2010). Briefly, parkinsonian disability was rated for 5 min every 10 min using a parkinsonian disability scale combining measures of range of movement, bradykinesia, posture, and attention/alertness. Range of movement was rated on a zero to nine scale (0, running, jumping between roof, walls, perch, using limbs through a wide range of activity; 9 , no movement). Bradykinesia was rated from zero to three ( 0 , normal initiation and speed of movement; 3 , prolonged freezing, akinesia, inability to move). Postural abnormalities were rated zero or one ( 0 , normal balance, upright posture, head held up; 1 , impaired balance, crouched posture, head down). Attention/alertness was rated zero or one ( 0 , normal head checking movements, movement of neck in variable directions, smooth, small movements; 1 , reduced or absent head checking, head in one position for $>50 \%$ of observation period). For parkinsonian disability, the score given was the one most representative of each 5 min observation period. A global parkinsonian disability score was rated as a combination of the behaviors mentioned above, equally weighted, according to the following formula: (range of movement $\times 1)+($ bradykinesia $\times 3)+($ posture $\times 9)+($ alertness $\times 9)$. The maximal parkinsonian disability score per $5 \mathrm{~min}$ observation period was 36 .

L-DOPA-induced dyskinesia and psychosis-like behaviors were also assessed. Dyskinesia were rated from zero to four (0, absent; 4 , severe, continuous, replacing normal activity, present $>70 \%$ of the observation period). Choreiform and dystonic dyskinesia were graded separately, and the dyskinesia score given reflected the most disabling dyskinesis observed, whether chorea or dystonia, in any 5 min period of assessment. Psychosis-like behaviors were rated in a similar manner to dyskinesia. The following behaviors were scored: hyperkinesia, response to nonapparent stimuli (hallucinatory behavior), repetitive grooming, and stereotypies. Each of these was rated from zero to four (0, absent; 1 , mild, present $<30 \%$ of time, and animal is still able to eat, drink, and perform normal activities; 2 , moderate, present $>30 \%$ of time, and animal is still able to eat, drink, and perform normal activities; 3 , marked, present $<30 \%$ of time, and animal is unable to eat, drink, and perform normal activities; 4 , severe, present $>30 \%$ of time, and animal is unable to eat, drink, and perform normal activities). For psychosis, the score attributed to each observation period was the most disabling of any of the four subscores observed in that 5 min period.

Parkinsonian disability, dyskinesia, and psychosis-like behavior scores were cumulated for each hour across the entire $6 \mathrm{~h}$ of observations and during the peak effect period (60-150 min after L-DOPA administration). The duration of antiparkinsonian benefit, i.e., ON-time, was defined as the number of minutes for which bradykinesia was absent. ONtime was further divided as "good" or "bad" quality, depending on the severity of dyskinesia present. Thus, good-quality ON-time was defined as the number of minutes when bradykinesia was zero, and dyskinesia were either absent, mild, or moderate in intensity (scores of 0,1 , and 2), whereas bad-quality ON-time was defined as the number of minutes during which bradykinesia was zero, and dyskinesia were either marked or severe (scores of 3 and 4). Similarly, ON-time with psychosis-like behavior was defined as the number of minutes for which bradykinesia was absent and in which psychosis-like behavior was present. ON-time with nondisabling psychosis-like behavior was defined as the number of minutes during which bradykinesia was zero and psychosis-like behavior was either absent, mild, or moderate in intensity (scores of 0,1 , and 2), whereas $\mathrm{ON}$-time with disabling psychosis-like behavior was defined as the number of minutes during which bradykinesia was zero and psychosis-like behavior was either marked or severe (scores of 3 and 4).

Statistical analysis. Categorical, discontinuous scores for parkinsonian disability, dyskinesia, and psychosis-like behavior severity were analyzed using nonparametric Friedman's followed by Dunn's multiple comparison post hoc tests. ON-time data were analyzed by one-way repeatedmeasures (RM) ANOVA followed by Tukey's multiple comparison post hoc tests. Time-course data for parkinsonian disability and dyskinesia scores were ranked by marmoset across each of the four treatments and analyzed by a two-way RM ANOVA followed by Bonferroni's multiple comparison tests. Statistical significance was assigned when $p<0.05$. Analyses were performed using GraphPad Prism 5.03.

\section{Results}

\section{Pharmacological profile of $R$ - and S-MDMA}

$R$-MDMA exhibited moderate affinity for $5-\mathrm{HT}_{2 \mathrm{~A}}$ receptors $\left(K_{\mathrm{i}}=\right.$ $4.7 \pm 1.1 \mu \mathrm{M})$ and lower affinity for SERT $\left(K_{\mathrm{i}}=24.5 \pm 0.8 \mu \mathrm{M}\right)$. $R$-MDMA exhibited no appreciable affinity for either $5-\mathrm{HT}_{1 \mathrm{~A}}$ receptors, NET, or DAT $\left(K_{\mathrm{i}}>50 \mu \mathrm{M}\right)$ (Table 2$)$. In contrast, $S$-MDMA exhibited no affinity at $5-\mathrm{HT}_{1 \mathrm{~A}}$ and $5-\mathrm{HT}_{2 \mathrm{~A}}$ receptors $\left(K_{\mathrm{i}}>50 \mu \mathrm{M}\right)$, but high affinity for SERT $\left(K_{\mathrm{i}}=222 \pm 62 \mathrm{nM}\right)$ and moderate affinity at both DAT and NET $\left(K_{\mathrm{i}}=2.3 \pm 0.4 \mu \mathrm{M}\right.$ and $7.8 \pm 2.1 \mu \mathrm{M}$, respectively) (Table 2 ). 
Table 2. MDMA enantiomers binding profiles

\begin{tabular}{llllll}
\hline & $5-\mathrm{HT}_{1 \mathrm{~A}}$ & \multicolumn{1}{c}{$5-\mathrm{HT}_{2 \mathrm{~A}}$} & $\mathrm{NET}$ & SERT & DAT \\
\hline R-MDMA & $>50$ & $4.7 \pm 1.1$ & $>50$ & $24.5 \pm 0.8$ & $>50$ \\
S-MDMA & $>50$ & $31.80 \pm 7.60$ & $7.8 \pm 2.1$ & $0.22 \pm 0.06$ & $2.3 \pm 0.4$ \\
\hline
\end{tabular}

The affinity is provided as the mean $K_{\mathrm{i}}(\mu \mathrm{M}) \pm$ SEM of three independent experiments, each performed in triplicate.

dyskinesia time course

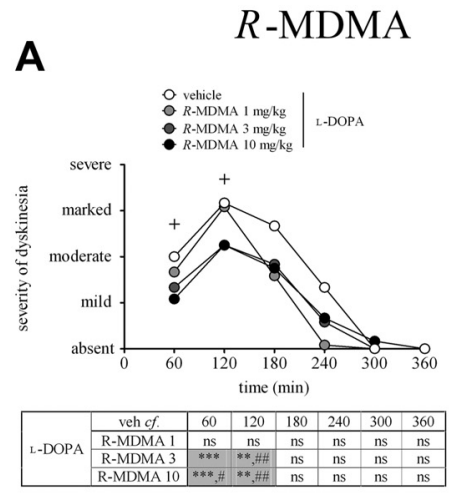

B

\section{$S$-MDMA}
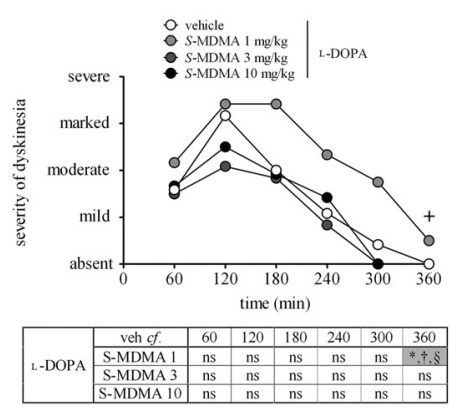

parkinsonism time course

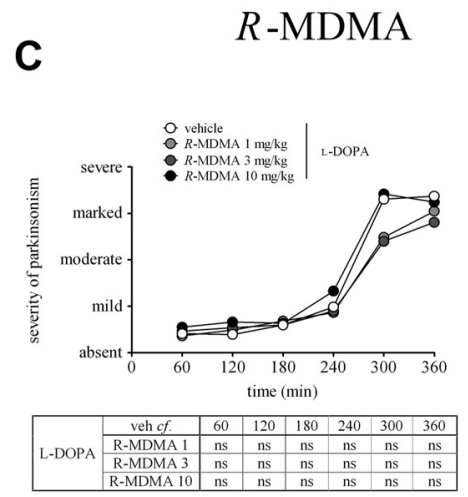

D

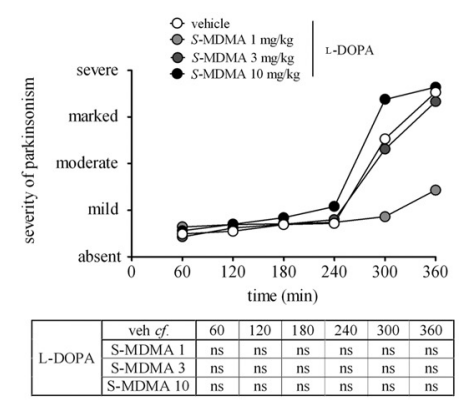

Figure 2. A, Time course of dyskinesia in marmosets treated with L-DOPA and $R-M D M A(1,3$, and $10 \mathrm{mg} / \mathrm{kg}$ ) or vehicle. $R$-MDMA (3 and $10 \mathrm{mg} / \mathrm{kg}$ ) significantly reduced the severity of L-DOPA-induced dyskinesia during the first $2 \mathrm{~h}$ of treatment, compared to L-DOPA vehicle treatment ( $p<0.001$ from $0-60 \mathrm{~min} ; p<0.01$ from 60-120 min) and L-DOPA $1 \mathrm{mg} / \mathrm{kg} R$-MDMA treatment ( $p<0.05$ for $10 \mathrm{mg} / \mathrm{kg}$ $R$-MDMAfrom $0-60 \mathrm{~min}$, and $p<0.01$ for 3 and $10 \mathrm{mg} / \mathrm{kg} R$-MDMAfrom $60-120 \mathrm{~min})$. Eachtimepointrepresentsthecumulated dyskinesiascore for every 5 min observation period during the preceding 60 min. The maximal possible score (most severe disability) was 24 . 0 n the $y$-axis, 6 is mild, 12 ismoderate, 18 ismarked, and 24 issevere. The crosses on the graph indicatetimepointsforwhichthere is significance. $\boldsymbol{B}$, Time course of dyskinesia inmarmosets treated with L-DOPA and S-MDMA $(1,3,10 \mathrm{mg} / \mathrm{kg})$ orvehicle.S-MDMA $(1 \mathrm{mg} / \mathrm{kg})$ significantly increased the severity of dyskinesiafrom 300 -360 min when compared to L-DOPA vehicle $(p<0.05)$. The severity of dyskinesia was also significantly higher when $1 \mathrm{mg} / \mathrm{kg}$ S-MDMA was compared to 3 and $10 \mathrm{mg} / \mathrm{kgS}$ S-MDMA (both $p<0.05$ ). Each timepointrepresents the cumulated dyskinesiascoreforevery 5 min observation period during the preceding $60 \mathrm{~min}$. Themaximal possiblescore (mostseveredisability) was 24 . 0 n they-axis, 6 is mild, 12 ismoderate, 18 is marked, and 24 is severe. The cross on the graph indicates a time point for which there is significance. C, Time course of parkinsonism in marmosets treated with L-DOPA and $R$-MDMA $(1,3,10 \mathrm{mg} / \mathrm{kg})$ or vehicle. $R$-MDMA had no effect on the antiparkinsonian action of L-DOPA ( $p>0.05)$. Each time point represents the cumulated parkinsonism score for every 5 min observation period during the preceding $60 \mathrm{~min}$. The maximal possible score (most severe disability) was 216. On the $y$-axis, 54 is mild, 108 is moderate, 162 is marked, and 216 is severe. D, Time course of parkinsonism in marmosets treated with L-DOPA and S-MDMA (1, 3, $10 \mathrm{mg} / \mathrm{kg})$ or vehicle. Each time point represents the cumulated parkinsonism score for every 5 min observation period during the preceding $60 \mathrm{~min}$. The maximal possible score (most severe disability) was 216.0n the $y$-axis, 54 is mild, 108 is moderate, 162 is marked, and 216 is severe. ${ }^{*} p<0.05$ when compared to L-DOPA vehicle; ${ }^{* *} p<0.01$ when compared to L-DOPA vehicle; ${ }^{* * *} p<0.001$ when compared to L-DOPA vehicle; $" p<0.05$ when compared to L-DOPA $1 \mathrm{mg} / \mathrm{kg}$ R-MDMA or S-MDMA; ${ }^{\# \#} p<0.01$ when compared to L-DOPA $1 \mathrm{mg} / \mathrm{kg}$ R-MDMA or S-MDMA; ${ }^{\S} p<0.05$ when compared to L-DOPA 3 $\mathrm{mg} / \mathrm{kg} R$-MDMA or S-MDMA; ${ }^{\dagger} p<0.05$ when compared to L-DOPA $10 \mathrm{mg} / \mathrm{kg} R$-MDMA or S-MDMA. The values represent the median score for parkinsonism/dyskinesia at each time point.

$R$-MDMA decreases the severity of L-DOPA-induced dyskinesia without reducing the antiparkinsonian action of $\mathrm{L}-\mathrm{DOPA}$ $R$-MDMA ( 3 and $10 \mathrm{mg} / \mathrm{kg}$ ) significantly reduced the severity of dyskinesia in the first $2 \mathrm{~h}$ of the observation period when admintension of ON-time was not observed with higher doses of $S$-MDMA (3 and $10 \mathrm{mg} / \mathrm{kg}$ ) with which duration of ON-time was significantly lower than in the $1 \mathrm{mg} / \mathrm{kg}$ treatment (by 21 and $30 \%$, respectively; $F_{(5,15)}=11.86, p<0.001$, one-way RM ANOVA; MDMA ( $P<0.01$, test). $R$-MDMA ( 3 and $10 \mathrm{mg} / \mathrm{kg}$ ) also reduced the severity of dyskinesia (both by $29 \%$ ) during the second hour of observation, when compared to animals treated with L-DOPA alone (both $p<0.01$, Bonferroni's post hoc test). When L-DOPA was combined with 3 and $10 \mathrm{mg} / \mathrm{kg}$ R-MDMA, the severity of peak-dose dyskinesia was reduced by 27 and 34\%, respectively, compared to L-DOPA alone [Freidman's statistic (FS) = 11.03, $p<0.01$; both $p<0.05$; Dunn's posthoc test] (Fig. 3A).

At no time during the observation period did $R$-MDMA impair the antiparkinsonian efficacy of L-DOPA (Fig. 2C). $R$-MDMA did not decrease the peak antiparkinsonian efficacy of L-DOPA (Fig. $4 A$ ). Additionally, $R$-MDMA did not alter duration of the ON-time (Fig. 5A). However, the duration of the ON-time with disabling dyskinesia was significantly reduced when $R$-MDMA ( 3 and $10 \mathrm{mg} / \mathrm{kg}$ ) was compared to L-DOPA alone (by 69 and $65 \%$, respectively; $F_{(5,15)}=8.061, p<$ 0.01 , one-way RM ANOVA; both $p<$ 0.01 , Tukey's post hoc test). $R$-MDMA at 3 and $10 \mathrm{mg} / \mathrm{kg}$ also significantly increased the duration of the ON-time with nondisabling dyskinesia, by 152 and 147\%, respectively $\left(F_{(5,15)}=6.773, p<0.01\right.$, one-way RM ANOVA; both $p<0.01$, Tukey's post hoc test), when compared to L-DOPA alone (Fig. 5C). Duration of the ON-time without disabling dyskinesia was also significantly enhanced by $R$ MDMA at 1,3 and $10 \mathrm{mg} / \mathrm{kg}\left(F_{(5,15)}=10.67\right.$, $p<0.001$, one-way RMANOVA; $p<0.05$ for $1 \mathrm{mg} / \mathrm{kg} R$-MDMA, $p<0.001$ for $3 \mathrm{mg} / \mathrm{kg}$ $R$-MDMA, $p<0.01$ for $10 \mathrm{mg} / \mathrm{kg} R$-MDMA, Tukey's post hoc test, data not shown).

\section{$S$-MDMA extends duration of} antiparkinsonian action of L-DOPA, but worsens the severity of dyskinesia $S$-MDMA significantly extended the duration of antiparkinsonian action of L-DOPA. Thus, $S$-MDMA (1 mg/kg) increased duration of ON-time, by $35 \%$, compared to vehicle $\left(F_{(5,15)}=11.86, p<\right.$ 0.001 , one-way RM ANOVA; $p<0.01$, Tukey's post hoc test) (Fig. 5D). This existered with L-DOPA (Fig. 2 A). Thus, the severity of dyskinesia
was reduced by 33 and $46 \%$, respectively, during the first hour, when 3 and $10 \mathrm{mg} / \mathrm{kg} R$-MDMA was compared to L-DOPA alone
$\left(F_{\text {time }(5,90)}=1.00, \mathrm{i}\right] \mathrm{p}>0.05 ; F_{\text {treatment }(3,90)}=10.14, p<0.0001$; and teraction $(20,90)=2.685, p<0.01$; two-way RM ANOVA, both $p<$ . 


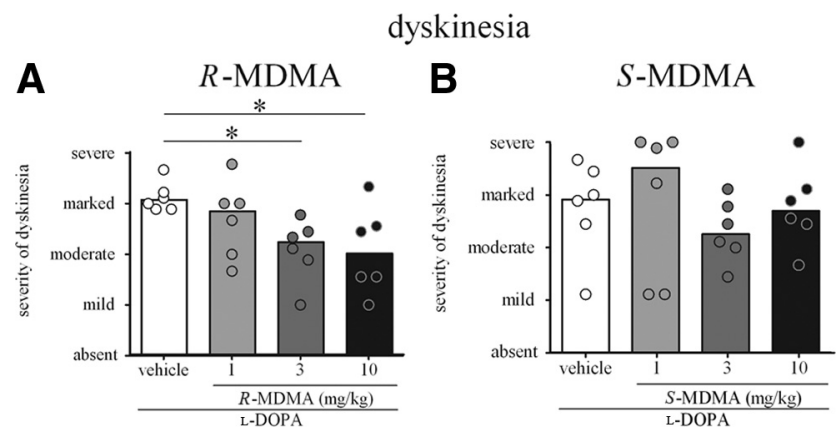

Figure 3. $A$, Peak-dose dyskinesia (60-150 min after L-DOPA administration) in marmosets treated with L-DOPA and R-MDMA (1, 3, or $10 \mathrm{mg} / \mathrm{kg}$ ) or vehicle. $R$-MDMA (3 and $10 \mathrm{mg} / \mathrm{kg}$ ) significantly reduced the severity of peak-dose dyskinesia when compared to L-DOPA vehicle (both $p<0.05$ ). B, Peak-dose dyskinesia (60-150 min after L-DOPA administration) in marmosets treated with L-DOPA and S-MDMA $(1,3$, or $10 \mathrm{mg} / \mathrm{kg})$ or vehicle. S-MDMA did not significantly alter the severity of peak-dose dyskinesia $(p>0.05) .{ }^{*} p<0.05$ when compared to L-DOPA vehicle. The bars represent the median score for dyskinesia, and the dots represent the individual score of each animal. The maximal possible score (most severe disability) was 36. On the $y$-axis, 9 is mild, 18 is moderate, 27 is marked, and 36 is severe.

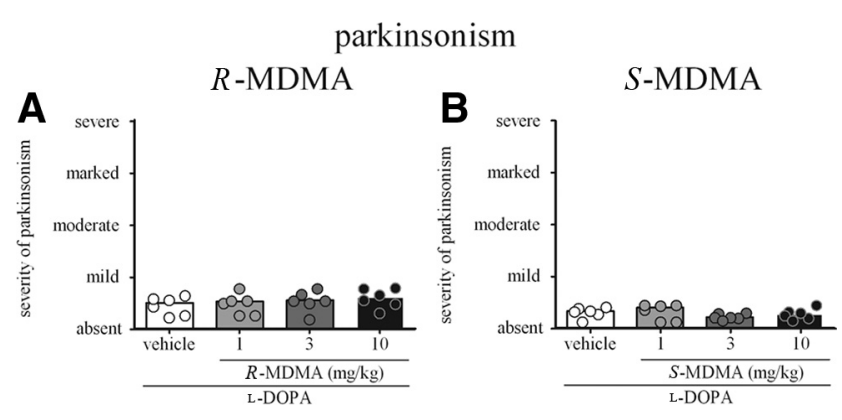

Figure 4. $A$, Peak-dose parkinsonism (60-150 min after L-DOPA administration) in marmosets treated with L-DOPA and $R$-MDMA $(1,3$, or $10 \mathrm{mg} / \mathrm{kg})$ or vehicle. $R$-MDMA did not alter the peak antiparkinsonian action of L-DOPA ( $p>0.05)$. B , Peak-dose parkinsonism (60-150 min after L-DOPA administration) in marmosets treated with L-DOPA and S-MDMA (1, 3, or $10 \mathrm{mg} / \mathrm{kg})$ or vehicle. S-MDMA did not alter the peak antiparkinsonian action of L-DOPA ( $p>0.05)$. The bars represent the median score for parkinsonism, and the dots represent the individual score of each animal. The maximal possible score (most severe disability) was 144 . On the $y$-axis, 36 is mild, 72 is moderate, 108 is marked, and 144 is severe.

$p<0.01$ between 1 and $3 \mathrm{mg} / \mathrm{kg} S$-MDMA; $p<0.001$ between 1 and $10 \mathrm{mg} / \mathrm{kg} S$-MDMA, Tukey's post hoc test).

However, in addition to extending duration of antiparkinsonian actions of L-DOPA, S-MDMA also increased the severity of dyskinesia (Fig. $2 B$ ). Thus, the severity of dyskinesia was significantly higher in the last hour of assessment, 300-360 min after L-DOPA administration when $1 \mathrm{mg} / \mathrm{kg} S$-MDMA was combined with L-DOPA, compared to L-DOPA alone $\left(F_{\text {time }(5,120)}=0.00\right.$, $p>0.05 ; F_{\text {treatment }(3,120)}=9.035, p<0.0001 ; F_{\text {interaction }(15,120)}=$ 0.7313, $p>0.05$, two-way ANOVA; $p<0.05$, Bonferroni's post hoc test) as well as compared to 3 and $10 \mathrm{mg} / \mathrm{kg} S$-MDMA (both $p<0.05$, Bonferroni's post hoc test). Higher doses of $S$-MDMA (3 and $10 \mathrm{mg} / \mathrm{kg}$ ) did not increase the severity of end of dose dyskinesia (Fig. $2 B$ ). The severity of peak-dose dyskinesia was not increased by any dose of $S$-MDMA (Fig. $3 B$ ). S-MDMA did not significantly alter the duration of $\mathrm{ON}$-time with disabling dyskinesia (Fig. 5E).

\section{Effects of $R$ - and $S$-MDMA on L-DOPA-induced} psychosis-like behavior

As displayed in Figure 6, $R$-MDMA exerted a beneficial effect on L-DOPA-induced psychosis-like behavior. Thus, R-MDMA (3 and $10 \mathrm{mg} / \mathrm{kg}$ ) significantly reduced duration of ON-time with disabling psychosis-like behavior when compared to the L-DOPA and vehicle treatments (by 59 and $45 \%$, respectively; $F_{(5,15)}=$ 5.465, $p<0.01$, one-way RM ANOVA; $p<0.01$ for $3 \mathrm{mg} / \mathrm{kg}$ $R$-MDMA, $p<0.05$ for $10 \mathrm{mg} / \mathrm{kg} R$-MDMA, Tukey's post hoc test) (Fig. $6 B$ ). When compared to the vehicle treatment, $R$-MDMA (3 mg/kg) increased duration of ON-time with nondisabling psychosis-like behavior (by 109\%; $F_{(5,15)}=5.580, p<$ 0.01 , one-way RM ANOVA; $p<0.01$, Tukey's post hoc test) (Fig. $6 C$ ) and of ON-time without psychosis-like behavior (by $184 \%$; $F_{(5,15)}=3.617, p<0.05$, one-way RM ANOVA; $p<0.05$, Tukey's post hoc test) (Fig. 6D). R-MDMA ( 3 and $10 \mathrm{mg} / \mathrm{kg}$ ) also significantly increased duration of ON-time without disabling psychosislike behavior when compared to L-DOPA alone (by 133 and 79\%, respectively; $F_{(5,15)}=8.174, p<0.01$, one-way RM ANOVA; $p<$ 0.001 for $3 \mathrm{mg} / \mathrm{kg} R$-MDMA; $p<0.05$ for $10 \mathrm{mg} / \mathrm{kg} R$-MDMA, Tukey's post hoc test) (Fig. 6E). Despite a trend, $R$-MDMA did not reduce the severity of peak-dose psychosis-like behavior $(\mathrm{FS}=6.828 ; p=0.0628)$ (Fig. $6 F)$.

As displayed in Figure $6 G-L, S$-MDMA had no effect on duration of ON-time with psychosis-like behavior, disabling or not, or on severity of peak psychosis-like behavior when compared to L-DOPA alone. However, ON-time without psychosis-like behavior was significantly longer in the $1 \mathrm{mg} / \mathrm{kg}$ treatment than in the $10 \mathrm{mg} / \mathrm{kg}$ treatment $\left(F_{(5,15)}=3.394, p<0.05\right.$, one-way RM ANOVA; $p<0.05$, Tukey's post hoc test).

\section{Discussion}

A novel synthesis of MDMA enantiomers allowed us to confirm that they exhibit different pharmacological profiles and demonstrate that they produce qualitatively different behavioral effects when administered in combination with L-DOPA to the MPTPlesioned marmoset. $R$-MDMA, a relatively selective compound for $5-\mathrm{HT}_{2 \mathrm{~A}}$ receptors, decreased severity of peak-dose dyskinesia and increased duration of good ON-time; S-MDMA, a compound exhibiting high affinity for SERT and moderate affinity for DAT, extended total duration of $\mathrm{ON}$-time but exacerbated dyskinesia. These results demonstrate that reducing $5-\mathrm{HT}_{2 \mathrm{~A}}$ receptormediated transmission is likely the primary mechanism by which racemic MDMA reduces dyskinesia, and identify dual SERT $>$ DAT inhibitors as promising agents to increase ON-time duration.

\section{Technical considerations: $R$ - and $S$-MDMA binding profile}

The affinity of $R$-MDMA for $5-\mathrm{HT}_{2 \mathrm{~A}}$ receptors, $4.7 \mu \mathrm{M}$, is in accordance with previous studies (Lyon et al., 1986; Battaglia et al., 1988). These two studies also demonstrated that MDMA and its enantiomers bind to $5-\mathrm{HT}_{1 \mathrm{~A}}$ receptors; however, they used $\left[{ }^{3} \mathrm{H}\right]-5-\mathrm{HT}$ as the radioligand and unlabeled $5-\mathrm{HT}$ as the displacer, making the assays nonspecific. Very few studies addressed the affinity of MDMA enantiomers for the monoamine transporters and, to our knowledge, our study is the first to assess the affinity of $R$ - and $S$-MDMA at a range of monoamine transporters using the modern, well-characterized, and highly selective radioligands $\left[{ }^{3} \mathrm{H}\right]$-citalopram, $\left[{ }^{3} \mathrm{H}\right]-\mathrm{GBR} 12935$, and $\left[{ }^{3} \mathrm{H}\right]$-nisoxetine. Although there are some minor discrepancies in absolute affinities reported, the relative affinities of the compounds for any given receptor and transporter are in agreement with the literature (Lyon et al., 1986; Battaglia et al., 1988; Verrico et al., 2007).

\section{$5-\mathrm{HT}_{2 \mathrm{~A}}$ receptors and dyskinesia}

The effects and pharmacology of R-MDMA support a role for $5-\mathrm{HT}_{2 \mathrm{~A}}$ antagonists as antidyskinetic agents (Maertens de Noordhout and Delwaide, 1986; Meco et al., 1988; Roberts, 2006; Visanji et 

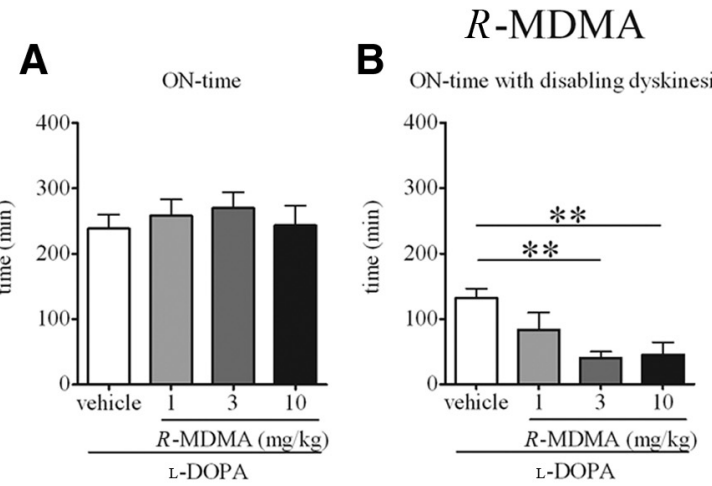

C
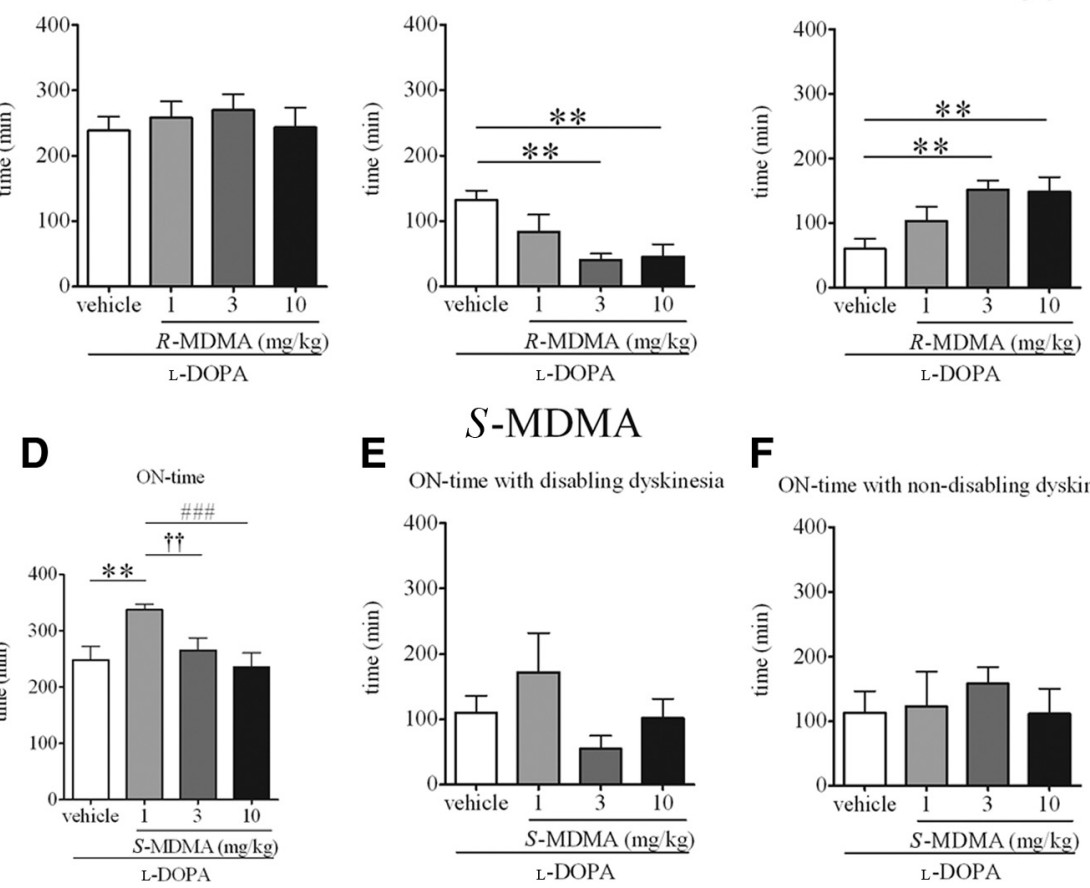

$\mathbf{F}$

ON-time with non-disabling dyskinesia

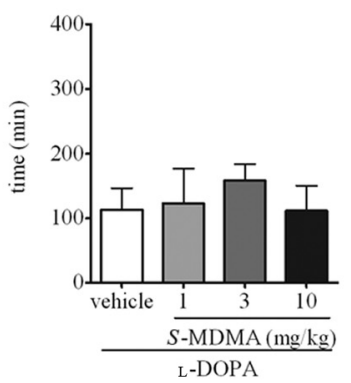

Figure 5. A, Duration of ON-time in marmosets treated with L-DOPA and $R$-MDMA $(1,3$, or $10 \mathrm{mg} / \mathrm{kg})$ or vehicle. $R$-MDMA had no effect on the duration of ON-time $(p>0.05)$. $\boldsymbol{B}$, Duration of ON-time with disabling dyskinesia in marmosets treated with L-DOPA and $R$-MDMA $(1,3$, or $10 \mathrm{mg} / \mathrm{kg}$ ) or vehicle. $R-M D M A$ ( 3 and $10 \mathrm{mg} / \mathrm{kg}$ ) significantly reduced the duration of $0 \mathrm{~N}$-time with disabling dyskinesia when compared to L-DOPA vehicle (both $p<0.01$ ). C, Duration of ON-time with nondisabling dyskinesia in marmosets treated with L-DOPA and $R$-MDMA $(1,3$, or $10 \mathrm{mg} / \mathrm{kg}$ ) or vehicle. $R$-MDMA ( 3 and $10 \mathrm{mg} / \mathrm{kg}$ ) significantly increased the duration of ON-time with nondisabling dyskinesia when compared to L-DOPA vehicle (both $p<0.01$ ). D. Duration of ON-time in marmosets treated with L-DOPA and S-MDMA $(1,3$, or $10 \mathrm{mg} / \mathrm{kg})$ or vehicle. S-MDMA $(1 \mathrm{mg} / \mathrm{kg})$ significantly increased duration of ON-time when compared to L-DOPA vehicle $(p<0.01)$. This extension of ON-time was not maintained when higher doses of S-MDMA ( 3 and $10 \mathrm{mg} / \mathrm{kg}$ ) were administered ( $p<0.01$ when $1 \mathrm{mg} / \mathrm{kg}$ S-MDMA was compared to $3 \mathrm{mg} / \mathrm{kg} \mathrm{S-MDMA;} p<0.001$ when $1 \mathrm{mg} / \mathrm{kg}$ S-MDMA was compared to $10 \mathrm{mg} / \mathrm{kg}$ S-MDMA). $\boldsymbol{E}$, Duration of ON-time with disabling dyskinesia in marmosets treated with L-DOPA and S-MDMA $(1,3$, or $10 \mathrm{mg} / \mathrm{kg})$ or vehicle. S-MDMA had no significant effect on duration of ON-time with disabling dyskinesia $(p>0.05)$. $\boldsymbol{F}$, Duration of ON-time with nondisabling dyskinesia in marmosets treated with L-DOPA and S-MDMA $(1,3$, or $10 \mathrm{mg} / \mathrm{kg})$ or vehicle. S-MDMA had no effect on duration of ON-time with nondisabling dyskinesia $(p>0.05)$ ${ }^{* *} p<0.01$ when compared to L-DOPA-vehicle; ${ }^{{ }^{\dagger}} p<0.01$ when $1 \mathrm{mg} / \mathrm{kg}$ S-MDMA is compared to $3 \mathrm{mg} / \mathrm{kg} \mathrm{S-MDMA;}{ }^{\# \# \#} p<$ 0.001 when $1 \mathrm{mg} / \mathrm{kg}$ S-MDMA is compared to $10 \mathrm{mg} / \mathrm{kg}$ S-MDMA. The values represent the mean \pm SEM ON-time duration. neurotransmission. Such a modulation of corticostriatal glutamatergic transmission by the selective $5-\mathrm{HT}_{2 \mathrm{~A}}$ antagonist volinanserin $(\mathrm{M} 100,907)$ was demonstrated in the MPTP-lesioned mouse (Ferguson et al., 2010).

Another mechanism by which $5-\mathrm{HT}_{2 \mathrm{~A}}$ antagonists alleviate L-DOPA-induced dyskinesia severity might be via an interaction with dopaminergic $\mathrm{D}_{1}$ receptors, which are thought to play a central role in the pathophysiology of dyskinesia (Jenner, 2008). Indeed, in the 6-OHDA-lesioned rat, M100,907 effectively reduced hyperlocomotion (Bishop et al., 2005) and controlateral rotations (Taylor et al., 2006) induced by the $\mathrm{D}_{1}$ agonist $N$-allyl-b-chloro-2,3,4,5tetrahydro-1-phenyl-1 $\mathrm{H}$-3-benzapine-7,8diol (SKF-82,958).

However, $R$-MDMA is not a $5-\mathrm{HT}_{2 \mathrm{~A}}$ antagonist, but a $5-\mathrm{HT}_{2 \mathrm{~A}}$ partial agonist that elicits $10 \%$ of 5-HT-elicited response (Nash et al., 1994). Dopamine is also a partial agonist at $5-\mathrm{HT}_{2 \mathrm{~A}}$ receptors, at which it elicits $60 \%$ of 5 -HT-elicited response (Bhattacharyya et al., 2006). Thus, although $R$-MDMA elicits a weak response at $5-\mathrm{HT}_{2 \mathrm{~A}}$ receptors, it acts as an antagonist when compared to dopamine, as it dampens dopamine-induced activation of $5-\mathrm{HT}_{2 \mathrm{~A}}$ receptors.

Our results do not support a $5-\mathrm{HT}_{1 \mathrm{~A}^{-}}$ mediated mechanism of action for MDMA antidyskinetic efficacy (Bishop et al., 2006). Direct actions are unlikely, since neither of the two enantiomers exhibit affinity for $5-\mathrm{HT}_{1 \mathrm{~A}}$ receptors. Second, an indirect 5- $\mathrm{HT}_{1 \mathrm{~A}}$-mediated mechanism would be mediated by S-MDMA, which inhibits 5-HT reuptake; in the current study, S-MDMA exacerbated dyskinesia severity. al., 2006; Vanover et al., 2008). However, the molecules assessed in these studies are not entirely selective for $5-\mathrm{HT}_{2 \mathrm{~A}}$ receptors and, if antagonizing $5-\mathrm{HT}_{2 \mathrm{~A}}$ receptors is believed to represent their primary antidyskinetic mechanism, other mechanisms may also contribute. The mechanisms underlying such antidyskinetic effects remain unclear. However, $5-\mathrm{HT}_{2 \mathrm{~A}}$ receptor levels are increased in the striatum and motor cortex of dyskinetic MPTPlesioned macaques (Huot et al., 2010a), suggesting that enhanced $5-\mathrm{HT}_{2 \mathrm{~A}}$-mediated corticostriatal neurotransmission underlies the dyskinetic state. Thus, stimulation of presynaptic $5-\mathrm{HT}_{2 \mathrm{~A}}$ receptors increases glutamate release (Aghajanian and Marek, 1997), and stimulation of postsynaptic 5- $\mathrm{HT}_{2 \mathrm{~A}}$ receptors increases NMDAmediated depolarization (Rahman and Neuman, 1993), so enhanced stimulation of corticostriatal $5-\mathrm{HT}_{2 \mathrm{~A}}$ receptors would increase excitation along this pathway. According to the classic model of the basal ganglia (Parent et al., 2000), enhanced excitation along the corticostriatal pathway results in greater excitation of the striatofugal neurons targeting the output structures of the basal ganglia, resulting in dyskinesia. By antagonizing $5-\mathrm{HT}_{2 \mathrm{~A}}$ receptors, $R$ MDMA would prevent this increase in corticostriatal glutamatergic

\section{Serotonergic and dopaminergic transporters inhibition and} ON-time extension

Monoamine reuptake inhibitors represent promising compounds in PD treatment. Thus, the selective DAT inhibitor GBR 12909 improved parkinsonism as monotherapy in the MPTPlesioned marmoset (Hansard et al., 2002). In small clinical studies, the dual DAT/NET inhibitor nomifensine improved parkinsonism as monotherapy (Park et al., 1981), whereas the triple monoamine reuptake blocker tesofensine was not effective (Hauser et al., 2007). In another clinical study, nomifensine, in combination with L-DOPA, produced mild antiparkinsonian benefit but worsened dyskinesia (Park et al., 1977), whereas it failed to show any benefit in another trial (Bedard et al., 1977). These studies suggest that although DAT inhibition might provide some antiparkinsonian benefit, the relative activity of compounds across the three transporters is probably critical for modulating L-DOPA actions.

Unlike GBR 12909, tesofensine, and nomifensine, S-MDMA preferentially inhibits SERT and DAT (SERT/DAT ratio of 10/1). Such a monoamine reuptake inhibition profile might be more suitable to extend ON-time duration. However, although 


\section{$R$-MDMA}
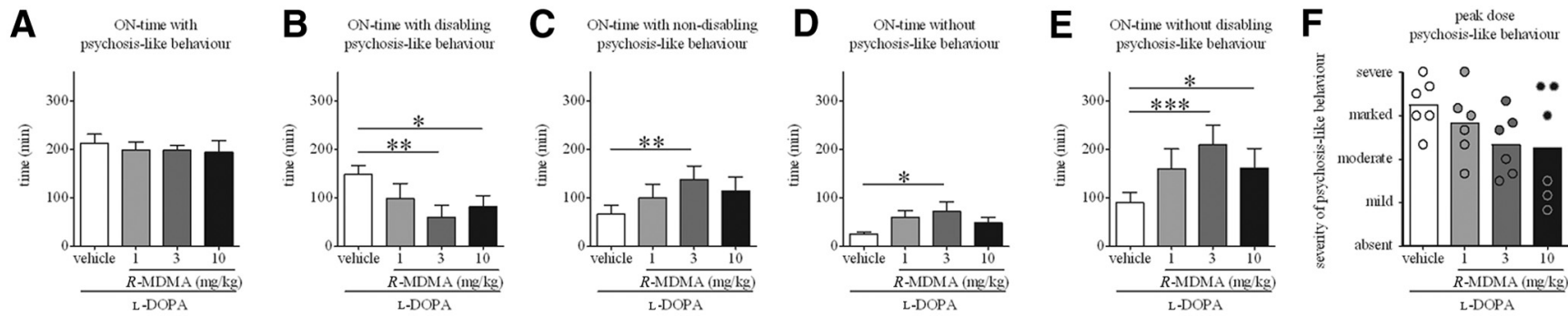

\section{$S$-MDMA}
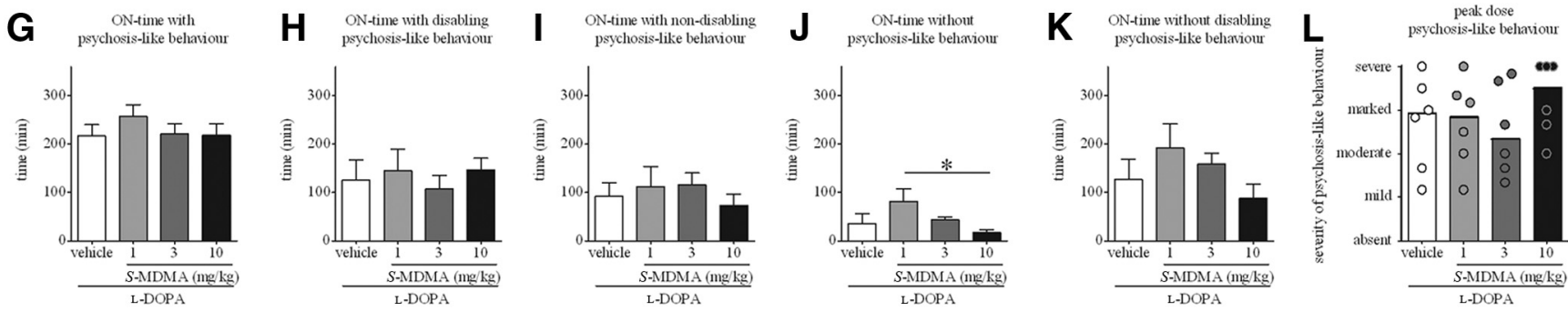

Figure 6. A, Duration of ON-time with psychosis-like behavior in marmosets treated with L-DOPA and R-MDMA $(1,3$, or $10 \mathrm{mg} / \mathrm{kg})$ or vehicle. $R$-MDMA had no effect on the duration of ON-time with psychosis-like behavior ( $p>0.05$ ). $\boldsymbol{B}$, Duration of ON-time with disabling psychosis-like behavior in marmosets treated with L-D0PA and $R$-MDMA (1, 3, or 10 mg/kg) or vehicle. $R$-MDMA (3 and $10 \mathrm{mg} / \mathrm{kg}$ ) significantly decreased the duration of $0 \mathrm{~N}$-time with disabling psychosis-like behavior when compared to L-DOPA vehicle ( $p<0.01$ for $3 \mathrm{mg} / \mathrm{kg} R$-MDMA; $p<0.05$ for $10 \mathrm{mg} / \mathrm{kg}$ R-MDMA). C, Duration of ON-time with nondisabling psychosis-like behavior in marmosets treated with L-DOPA and R-MDMA (1, 3, or $10 \mathrm{mg} / \mathrm{kg})$ or vehicle. $R$-MDMA (3 mg/kg) significantly increased the duration of $0 \mathrm{~N}$-time with nondisabling psychosis-like behavior when compared to L-DOPA vehicle $(p<0.01)$. D, Duration of ON-time without psychosis-like behavior in marmosets treated with L-DOPA and R-MDMA (1, 3, or $10 \mathrm{mg} / \mathrm{kg})$ or vehicle. $R$-MDMA (3 mg/kg) significantly increased the duration of ON-time without psychosis-like behavior when compared to L-DOPA vehicle $(p<0.05)$. E, Duration of ON-time without disabling psychosis-like behavior in marmosets treated with L-DOPA and $R$-MDMA (1, $3,0 \mathrm{r} 10 \mathrm{mg} / \mathrm{kg})$ or vehicle. $R$-MDMA ( 3 and $10 \mathrm{mg} / \mathrm{kg}$ ) significantly increased the duration of ON-time without disabling psychosis-like behavior when compared to L-D0PA vehicle ( $p<0.001 \mathrm{for} 3 \mathrm{mg} / \mathrm{kg} R$-MDMA; $p<0.05$ for $10 \mathrm{mg} / \mathrm{kg} R$-MDMA). F, Peak-dose psychosis-like behavior (60-150 min after L-DOPA administration) in marmosets treated with L-DOPA and $R$-MDMA (1, 3, or $10 \mathrm{mg} / \mathrm{kg})$ or vehicle. $R$-MDMA did not significantly alter the severity of peak-dose dyskinesia ( $p>0.05$ ). G, Duration of ON-time with psychosis-like behavior in marmosets treated with L-DOPA and S-MDMA (1, 3, or 10 mg/kg) or vehicle. S-MDMA had no effect on the duration of ON-time with psychosis-like behavior $(p>0.05)$. $\boldsymbol{H}$, Duration of ON-time with disabling psychosis-like behavior in marmosets treated with L-DOPA and S-MDMA (1, 3, or $10 \mathrm{mg} / \mathrm{kg}$ ) or vehicle. S-MDMA had no effect on the duration of ON-time with disabling psychosis-like behavior ( $p>0.05)$. I, Duration of $0 \mathrm{~N}$-time with nondisabling psychosis-like behavior in marmosets treated with L-DOPA and S-MDMA (1,3, or $10 \mathrm{mg} / \mathrm{kg}$ ) or vehicle. S-MDMA had no effect on the duration of ON-time with nondisabling psychosis-like behavior ( $p>0.05)$. J, Duration of ON-time without psychosis-like behavior in marmosets treated with L-DOPA and S-MDMA (1, 3, or $10 \mathrm{mg} / \mathrm{kg})$ or vehicle. Duration of ON-time without psychosis-like behavior was significantly longer in the 1 $\mathrm{mg} / \mathrm{kg} S$-MDMA treatment when compared to the $10 \mathrm{mg} / \mathrm{kg}$ S-MDMA treatment $(p<0.05)$. $\boldsymbol{K}$, Duration of ON-time without disabling psychosis-like behavior in marmosets treated with L-DOPA and S-MDMA $(1,3$, or $10 \mathrm{mg} / \mathrm{kg})$ or vehicle. S-MDMA had no effect on the duration of ON-time without disabling psychosis-like behavior $(p>0.05)$. $L$, Peak-dose psychosis-like behavior (60-150 min after L-DOPA administration) in marmosets treated with L-DOPA and S-MDMA (1,3, or $10 \mathrm{mg} / \mathrm{kg}$ ) or vehicle. S-MDMA did not significantly alter the severity of peak-dose dyskinesia ( $p>0.05)$. Data are presented as the mean \pm SEM ON-time duration $(\boldsymbol{A}-\boldsymbol{E}, \mathbf{G}-\boldsymbol{K}) . \boldsymbol{F}, \boldsymbol{L}$, Bars represent the median score for psychosis-like behavior, and the dots represent the individual score of each animal; the maximal possible score (most severe disability) was 36 . For graphs $\boldsymbol{F}$ and $\boldsymbol{L}$, on the $y$-axis, 9 is mild, 18 is moderate, 27 is marked, and 36 is severe. ${ }^{*} p<0.05$; $^{* *} p<0.01 ;{ }^{* * *} p<0.001$.

S-MDMA did not increase the severity of peak-dose dyskinesia, it increased the duration of ON-time with dyskinesia, somewhat offsetting the benefits of ON-time extension. Nonetheless, benefits of reduction of OFF-time have been appreciated in the clinic, even if the supplementary ON-time is associated with dyskinesia (Rinne et al., 1998; Parkinson Study Group, 2005).

The relative contribution of SERT and DAT inhibition to ONtime extension achieved with S-MDMA is unclear. Although DAT inhibition is an appealing mechanism, MPTP administration to marmosets leads to $>90 \%$ reduction in striatal dopamine uptake (Jenner et al., 1984), making a striatal site of action unlikely. More likely, though hypothetically, would be an action where dopamine terminals are relatively intact, for instance, frontal cortex, where enhancing dopaminergic function might enhance motor function. Such cortical effects on DAT may synergize with a striatal effect on SERT. Striatal serotonergic terminals are likely to participate in the reuptake of dopamine synthesized from L-DOPA (Berger, 1978; Berger and Glowinski, 1978). Thus, SERT inhibitors could prolong dopamine actions, accounting for the extension of ON-time obtained with $S$-MDMA. However, this in itself is insufficient as selective
SERT inhibitors do not produce similar effects (Hansard et al., 2002).

$S$-MDMA action on SERT likely accounts for the fact that ON-time extension was compromised by dyskinesia. Conversion of L-DOPA into dopamine in raphestriatal terminals is thought to be an important determinant in dyskinesia pathophysiology (Carta et al., 2007). Thus, inhibiting SERT would exacerbate nonphysiological dopaminergic transmission, as striatal serotonergic terminals participate in the reuptake of dopamine. Furthermore, although speculative, inhibiting SERT would also result in less 5 -HT being reuptaken into the presynaptic cleft, allowing for more dopamine to be packed into vesicles, which would exacerbate nonphysiologic dopamine release. However, a study performed in the 6-OHDA-lesioned rat demonstrated that chronic treatment with the SERT inhibitor citalopram reduces dyskinesia severity after 2 months of daily administration (Kuan et al., 2008). It remains to be established whether chronic daily treatment with a dual SERT $>$ DAT inhibitor would also reduce dyskinesia severity.

The extension of ON-time obtained with $S$-MDMA $1 \mathrm{mg} / \mathrm{kg}$ was not maintained at higher doses. This phenomenon might be 
explained by neurotransmitter depletion at higher doses of $S$-MDMA. Indeed, after its binding with monoamine transporters, MDMA inhibits monoamine uptake and reverses transport direction, promoting neurotransmitter release (Fleckenstein et al., 2007) and depleting presynaptic vesicles (Mlinar and Corradetti, 2003). It is thus possible that higher doses of $S$-MDMA led to an early exhaustion of presynaptic neurotransmitters, explaining their failure to extend ON-time.

\section{MDMA enantiomers and dopaminergic psychosis-like behaviors}

$R$-MDMA exerted a favorable effect on L-DOPA-induced psychosis-like behavior. These results support the potential efficacy of $5-\mathrm{HT}_{2 \mathrm{~A}}$ antagonists against $\mathrm{PD}$ dopaminergic psychosis demonstrated previously with ACP-103 (Meltzer et al., 2010). The data are also in accordance with two recent anatomical studies which found increased $5-\mathrm{HT}_{2 \mathrm{~A}}$ receptor levels in the temporal cortex of PD patients with visual hallucinations (Ballanger et al., 2010; Huot et al., 2010b).

The findings of the present study demonstrate that dual SERT $>$ DAT inhibitors do not worsen the severity of dopaminergic psychosis-like behavior in the parkinsonian marmoset. This is important to know from a drug-development perspective, as enhancing dopaminergic transmission carries the risk of triggering psychiatric features (Merims and Giladi, 2008).

\section{Concluding remarks}

Racemic MDMA possesses unique activity since it alleviates L-DOPA-induced dyskinesia and, in an anecdotal case report, extended L-DOPA antiparkinsonian benefits. The data presented here expand our understanding of the mechanisms of MDMA actions in parkinsonism. Thus, MDMA antidyskinetic action likely comes from $R$-MDMA partial agonist activity at $5-\mathrm{HT}_{2 \mathrm{~A}}$ receptors, whereas $S$-MDMA SERT $>$ DAT inhibitory activity probably accounts for the ability of MDMA to extend L-DOPA antiparkinsonian action. Unfortunately, MDMA and its enantiomers are not good candidates for clinical development for PD because of psychoactivity (Shulgin and Nichols, 1978) and potential for neurotoxicity (O'Hearn et al., 1988). However, studies such as ours help to refine the understanding of interactions between the serotonergic and dopaminergic systems in PD, and might define pharmacological profiles of novel molecules that could represent leads for drug discovery programs.

\section{References}

Aghajanian GK, Marek GJ (1997) Serotonin induces excitatory postsynaptic potentials in apical dendrites of neocortical pyramidal cells. Neuropharmacology 36:589-599.

Ballanger B, Strafella AP, van Eimeren T, Zurowski M, Rusjan PM, Houle S, Fox SH (2010) Serotonin 2A receptors and visual hallucinations in Parkinson disease. Arch Neurol 67:416-421.

Battaglia G, Brooks BP, Kulsakdinun C, De Souza EB (1988) Pharmacologic profile of MDMA (3,4-methylenedioxymethamphetamine) at various brain recognition sites. Eur J Pharmacol 149:159-163.

BBC (2001) Ecstasy \& agony. Retrieved January 27, 2011. http://www.bbc.co.uk/science/horizon/2000/ecstasyagony.shtml.

Bedard P, Parkes JD, Marsden CD (1977) Nomifensine in Parkinson's disease. Br J Clin Pharmacol 4 [Suppl 2]:187S-190S.

Berger B (1978) In vitro uptake of dopamine in serotoninergic nerve terminals: a fluorescence histochemical study on vibratome sections of the rat cerebral cortex. Adv Biochem Psychopharmacol 19:405-408.

Berger B, Glowinski J (1978) Dopamine uptake in serotoninergic terminals in vitro: a valuable tool for the histochemical differentiation of catecholaminergic and serotoninergic terminals in rat cerebral structures. Brain Res 147:29-45.

Bhattacharyya S, Raote I, Bhattacharya A, Miledi R, Panicker MM (2006)
Activation, internalization, and recycling of the serotonin $2 \mathrm{~A}$ receptor by dopamine. Proc Natl Acad Sci U S A 103:15248-15253.

Bishop C, Daut GS, Walker PD (2005) Serotonin 5-HT2A but not 5-HT2C receptor antagonism reduces hyperlocomotor activity induced in dopamine-depleted rats by striatal administration of the D1 agonist SKF 82958. Neuropharmacology 49:350-358.

Bishop C, Taylor JL, Kuhn DM, Eskow KL, Park JY, Walker PD (2006) MDMA and fenfluramine reduce L-DOPA-induced dyskinesia via indirect 5-HT1A receptor stimulation. Eur J Neurosci 23:2669-2676.

Carta M, Carlsson T, Kirik D, Bjorklund A (2007) Dopamine released from 5-HT terminals is the cause of L-DOPA-induced dyskinesia in parkinsonian rats. Brain 130:1819-1833.

Chemel BR, Roth BL, Armbruster B, Watts VJ, Nichols DE (2006) WAY100635 is a potent dopamine D4 receptor agonist. Psychopharmacology (Berl) 188:244-251.

Cheng Y, Prusoff WH (1973) Relationship between the inhibition constant (K1) and the concentration of inhibitor which causes 50 per cent inhibition (I50) of an enzymatic reaction. Biochem Pharmacol 22:3099-3108.

Durif F, Debilly B, Galitzky M, Morand D, Viallet F, Borg M, Thobois S, Broussolle E, Rascol O (2004) Clozapine improves dyskinesias in Parkinson disease: a double-blind, placebo-controlled study. Neurology 62:381-388

Ferguson M, Nayyar T, Ansah TA (2010) 5-HT2A receptor antagonist M100907 decreases striatal extracellular glutamate in MPTP mouse model of Parkinson's disease. Soc Neurosci Abstr 36:52.11/M8.

Fleckenstein AE, Volz TJ, Riddle EL, Gibb JW, Hanson GR (2007) New insights into the mechanism of action of amphetamines. Annu Rev Pharmacol Toxicol 47:681-698.

Fox SH, Visanji NP, Johnston TH, Gomez-Ramirez J, Voon V, Brotchie JM (2006) Dopamine receptor agonists and levodopa and inducing psychosislike behavior in the MPTP primate model of Parkinson disease. Arch Neurol 63:1343-1344

Fox SH, Visanji N, Reyes G, Huot P, Gomez-Ramirez J, Johnston T, Brotchie JM (2010) Neuropsychiatric behaviors in the MPTP marmoset model of Parkinson's disease. Can J Neurol Sci 37:86-95.

Gandy MN, McIldowie M, Lewis K, Wasik AM, Salomonczyk D, Wagg K, Millar ZA, Tindiglia D, Huot P, Johnston T, Thiele S, Nguyen B, Barnes NM, Brotchie JM, Martin-Iverson MT, Nash J, Gordon J, Piggott M) (2010) Redesigning the designer drug ecstasy: non-psychoactive MDMA analogues exhibiting Burkitt's lymphoma cytotoxicity. Med Chem Commun 1:287-293.

Gomez-Ramirez J, Johnston TH, Visanji NP, Fox SH, Brotchie JM (2006) Histamine $\mathrm{H} 3$ receptor agonists reduce L-dopa-induced chorea, but not dystonia, in the MPTP-lesioned nonhuman primate model of Parkinson's disease. Mov Disord 21:839-846.

Hansard MJ, Smith LA, Jackson MJ, Cheetham SC, Jenner P (2002) Dopamine, but not norepinephrine or serotonin, reuptake inhibition reverses motor deficits in 1-methyl-4-phenyl-1,2,3,6-tetrahydropyridine-treated primates. J Pharmacol Exp Ther 303:952-958.

Hauser RA, Salin L, Juhel N, Konyago VL (2007) Randomized trial of the triple monoamine reuptake inhibitor NS 2330 (tesofensine) in early Parkinson's disease. Mov Disord 22:359-365.

Hely MA, Morris JG, Reid WG, Trafficante R (2005) Sydney Multicenter Study of Parkinson's disease: non-L-dopa-responsive problems dominate at 15 years. Mov Disord 20:190-199.

Hornykiewicz O, Kish SJ (1987) Biochemical pathophysiology of Parkinson's disease. Adv Neurol 45:19-34.

Huot P, Johnston TH, Winkelmolen L, Fox SH, Brotchie JM (2010a) 5-HT(2A) receptor levels increase in MPTP-lesioned macaques treated chronically with L-DOPA. Neurobiol Aging. Advance online publication. Retrieved June 17, 2010. doi:10.1016/j.neurobiolaging. 2010.1004.1035.

Huot P, Johnston TH, Darr T, Hazrati LN, Visanji NP, Pires D, Brotchie JM, Fox SH (2010b) Increased 5-HT2A receptors in the temporal cortex of parkinsonian patients with visual hallucinations. Mov Disord 25:1399-1408.

Iravani MM, Jackson MJ, Kuoppamaki M, Smith LA, Jenner P (2003) 3,4Methylenedioxymethamphetamine (ecstasy) inhibits dyskinesia expression and normalizes motor activity in 1-methyl-4-phenyl-1,2,3,6-tetrahydropyridine-treated primates. J Neurosci 23:9107-9115.

Jenner P (2008) Molecular mechanisms of L-DOPA-induced dyskinesia. Nat Rev Neurosci 9:665-677.

Jenner P, Rupniak NM, Rose S, Kelly E, Kilpatrick G, Lees A, Marsden CD 
(1984) 1-Methyl-4-phenyl-1,2,3,6-tetrahydropyridine-induced parkinsonism in the common marmoset. Neurosci Lett 50:85-90.

Kuan WL, Zhao JW, Barker RA (2008) The role of anxiety in the development of levodopa-induced dyskinesias in an animal model of Parkinson's disease, and the effect of chronic treatment with the selective serotonin reuptake inhibitor citalopram. Psychopharmacology (Berl) 197:279-293.

Lowry OH, Rosebrough NJ, Farr AL, Randall RJ (1951) Protein measurement with the Folin phenol reagent. J Biol Chem 193:265-275.

Lyon RA, Glennon RA, Titeler M (1986) 3,4-Methylenedioxymethamphetamine (MDMA): stereoselective interactions at brain 5-HT1 and 5-HT2 receptors. Psychopharmacology (Berl) 88:525-526.

Maertens de Noordhout A, Delwaide PJ (1986) Open pilot trial of ritanserin in parkinsonism. Clin Neuropharmacol 9:480-484.

Meco G, Marini S, Linfante I, Modarelli F, Agnoli A (1988) Controlled single-blind crossover study of ritanserin and placebo in L-dopa-induced dyskinesias in Parkinson's disease. Curr Ther Res 43:262-270.

Meltzer HY, Mills R, Revell S, Williams H, Johnson A, Bahr D, Friedman JH (2010) Pimavanserin, a serotonin(2A) receptor inverse agonist, for the treatment of Parkinson's disease psychosis. Neuropsychopharmacology 35:881-892.

Merims D, Giladi N (2008) Dopamine dysregulation syndrome, addiction and behavioral changes in Parkinson's disease. Parkinsonism Relat Disord 14:273-280.

Mlinar B, Corradetti R (2003) Endogenous 5-HT, released by MDMA through serotonin transporter- and secretory vesicle-dependent mechanisms, reduces hippocampal excitatory synaptic transmission by preferential activation of 5-HT1B receptors located on CA1 pyramidal neurons. Eur J Neurosci 18:1559-1571.

Nash JF, Roth BL, Brodkin JD, Nichols DE, Gudelsky GA (1994) Effect of the $\mathrm{R}(-)$ and $\mathrm{S}(+)$ isomers of MDA and MDMA on phosphatidyl inositol turnover in cultured cells expressing 5-HT2A or 5-HT2C receptors. Neurosci Lett 177:111-115.

Nenajdenko VG, Karpov AS, Balenkova ES (2001) A new convenient approach to chiral beta-aryl(heteroaryl)alkylamines. Tetrahedron Asymmetry 12:2517-2527.

Oh JD, Bibbiani F, Chase TN (2002) Quetiapine attenuates levodopainduced motor complications in rodent and primate parkinsonian models. Exp Neurol 177:557-564.

O’Hearn E, Battaglia G, De Souza EB, Kuhar MJ, Molliver ME (1988) Methylenedioxyamphetamine (MDA) and methylenedioxymethamphetamine (MDMA) cause selective ablation of serotonergic axon terminals in forebrain: immunocytochemical evidence for neurotoxicity. J Neurosci 8:2788-2803.

Parent A, Sato F, Wu Y, Gauthier J, Levesque M, Parent M (2000) Organization of the basal ganglia: the importance of axonal collateralization. Trends Neurosci 23:S20-S27.
Park DM, Findley LJ, Teychenne PF (1977) Nomifensine in parkinsonism. Br J Clin Pharmacol 4 [Suppl 2]:185S-186S.

Park DM, Findley LJ, Hanks G, Sandler M (1981) Nomifensine: effect in Parkinsonian patients not receiving levodopa. J Neurol Neurosurg Psychiatry 44:352-354.

Parkinson Study Group (2005) A randomized placebo-controlled trial of rasagiline in levodopa-treated patients with Parkinson disease and motor fluctuations: the PRESTO study. Arch Neurol 62:241-248.

Patel S, Freedman S, Chapman KL, Emms F, Fletcher AE, Knowles M, Marwood R, Mcallister G, Myers J, Curtis N, Kulagowski JJ, Leeson PD, Ridgill M, Graham M, Matheson S, Rathbone D, Watt AP, Bristow LJ, Rupniak NM, Baskin E, et al. (1997) Biological profile of L-745,870, a selective antagonist with high affinity for the dopamine D4 receptor. J Pharmacol Exp Ther 283:636-647.

Rahman S, Neuman RS (1993) Activation of 5-HT2 receptors facilitates depolarization of neocortical neurons by N-methyl-D-aspartate. Eur J Pharmacol 231:347-354.

Rinne UK, Larsen JP, Siden A, Worm-Petersen J (1998) Entacapone enhances the response to levodopa in parkinsonian patients with motor fluctuations. Nomecomt Study Group. Neurology 51:1309-1314.

Roberts C (2006) ACP-103, a 5-HT2A receptor inverse agonist. Curr Opin Investig Drugs 7:653-660.

Shulgin AT, Nichols DE (1978) Characterization of three new psychotomimetics. In: The psychopharmacology of hallucinogens (Stillman RC, Willette RE, eds), pp 74-83. New York: Pergamon.

Silverdale MA, Nicholson SL, Crossman AR, Brotchie JM (2005) Topiramate reduces levodopa-induced dyskinesia in the MPTP-lesioned marmoset model of Parkinson's disease. Mov Disord 20:403-409.

Taylor JL, Bishop C, Ullrich T, Rice KC, Walker PD (2006) Serotonin 2A receptor antagonist treatment reduces dopamine D1 receptor-mediated rotational behavior but not L-DOPA-induced abnormal involuntary movements in the unilateral dopamine-depleted rat. Neuropharmacology 50:761-768.

Vanover KE, Betz AJ, Weber SM, Bibbiani F, Kielaite A, Weiner DM, Davis RE, Chase TN, Salamone JD (2008) A 5-HT2A receptor inverse agonist, ACP-103, reduces tremor in a rat model and levodopa-induced dyskinesias in a monkey model. Pharmacol Biochem Behav 90:540-544.

Verrico CD, Miller GM, Madras BK (2007) MDMA (ecstasy) and human dopamine, norepinephrine, and serotonin transporters: implications for MDMA-induced neurotoxicity and treatment. Psychopharmacology (Berl) 189:489-503.

Visanji NP, Gomez-Ramirez J, Johnston TH, Pires D, Voon V, Brotchie JM, Fox SH (2006) Pharmacological characterization of psychosis-like behavior in the MPTP-lesioned nonhuman primate model of Parkinson's disease. Mov Disord 21:1879-1891. 